\title{
Lidar observation and model simulation of a volcanic-ash-induced cirrus cloud during the Eyjafjallajökull eruption
}

\author{
C. Rolf ${ }^{1}$, M. Krämer ${ }^{1}$, C. Schiller ${ }^{\dagger}$, M. Hildebrandt ${ }^{1}$, and M. Riese ${ }^{1}$ \\ ${ }^{1}$ Forschungszentrum Jülich, IEK-7, Jülich, Germany \\ $\dagger$ deceased \\ Correspondence to: C. Rolf (c.rolf@fz-juelich.de)
}

Received: 11 May 2012 - Published in Atmos. Chem. Phys. Discuss.: 22 June 2012

Revised: 26 October 2012 - Accepted: 29 October 2012 - Published: 6 November 2012

\begin{abstract}
Heterogeneous ice formation induced by volcanic ash from the Eyjafjallajökull volcano eruption in April 2010 is investigated based on the combination of a cirrus cloud observed with a backscatter lidar over Jülich (western Germany) and model simulations along backward trajectories. The microphysical properties of the cirrus cloud could only be represented by the microphysical model under the assumption of an enhanced number of efficient ice nuclei originating from the volcanic eruption. The ice nuclei (IN) concentration determined by lidar measurements directly before and after cirrus cloud occurrence implies a value of around $0.1 \mathrm{~cm}^{-3}$ (in comparison normal IN conditions: $0.01 \mathrm{~cm}^{-3}$ ). This leads to a cirrus cloud with rather small ice crystals having a mean radius of $12 \mu \mathrm{m}$ and a modification of the ice particle number $\left(0.08 \mathrm{~cm}^{-3}\right.$ instead of $3 \times 10^{-4} \mathrm{~cm}^{-3}$ under normal IN conditions). The effectiveness of ice nuclei was estimated by the use of the microphysical model and the backward trajectories based on ECMWF data, establishing a freezing threshold of around $105 \%$ relative humidity with respect to ice in a temperature range from -45 to $-55^{\circ} \mathrm{C}$. Only with these highly efficient ice nuclei was it possible for the cirrus cloud to be formed in a slightly supersaturated environment.
\end{abstract}

\section{Introduction}

The Eyjafjallajökull volcano in Iceland ejected a large ash cloud during its eruptions in April 2010. The cloud spread out over central Europe in a period of 6 days and severely disrupted the air traffic. The ash cloud was observed from ground (e.g. Ansmann et al., 2010; Gross et al., 2012; Seifert et al., 2011) and aircraft (e.g. Johnson et al., 2012; Schumann et al., 2011) and is well documented in several special issues (ACP, JGR, and Atmospheric Environment). Two days after the first large eruption on 14 April, we detected the ash cloud with a backscatter lidar system over Jülich, western Germany $\left(50^{\circ} 54^{\prime} \mathrm{N}, 6^{\circ} 24^{\prime} \mathrm{E}\right)$. Embedded in the ash plume a cirrus cloud is also observed.

The volcanic ash event provides a good opportunity to investigate the impact of volcanic ash particles on cirrus cloud formation in the atmosphere. At the moment, there is a lack of observations, and the influence of volcanic ash on heterogeneous freezing is a matter of controversy. Some studies state that volcanic ash particles act as good ice nuclei (IN) (e.g. Isono et al., 1959; Durant et al., 2008; Fornea et al., 2009; Prenni et al., 2009), while others suggest that the volcanic ash particles have no further impact as IN (e.g. Langer et al., 1974; Schnell and Delany, 1976). The heterogeneous freezing efficiency of the Eyjafjallajökull ash particles has been investigated in two previous studies (Hoyle et al., 2011; Steinke et al., 2011). Both studies used particle probes from ground near the volcano and found only moderate effects on atmospheric ice formation. Another study by Bingemer et al. (2012) shows a large increase of the IN concentration during the Eyjafjallajökull events on two sites near the surface. All these studies are based on IN that are directly sampled from the ground or using filter probes. IN efficiency was analyzed in a laboratory simulation chamber under controlled conditions. Seifert et al. (2011) studied the influence of Eyjafjallajökull ash on cloud formation using a lidar and found periods with induced cirrus clouds embedded in ash layers. They showed the existence of very efficient IN, which form ice crystals in an environment that is relatively dry and 
only few percent supersaturated. The study by Seifert et al. (2011) focuses on a real atmospheric observation of an ashinduced cirrus cloud with a lidar, whereas the present paper also shows lidar observation extended by investigations on the microphysical properties of induced cirrus clouds by model simulations. The formation of the cirrus cloud is analyzed by microphysical simulations along backward trajectories. The simulation provides information on the microphysical properties of the ash-induced cirrus cloud and conditions for the development of such clouds.

The lidar (short for light detection and ranging) measures optical properties (i.e. backscatter and extinction coefficient) and depolarization of particles at one wavelength with a high vertical resolution. In the depolarization channel, it is possible to distinguish various shapes of observed particles.

Periods with or without volcanic ash occurred in accordance with the dynamic situation. The largest amount of ash was found above the planetary boundary layer, below seven $\mathrm{km}$, in the free troposphere (Ansmann et al., 2010; Schumann et al., 2011). However, during some periods, our measurements show an increased depolarization and particle extinction signal at higher altitudes. This may have been due to pure volcanic ash, ice crystals or a mixture of the two. In this study, we investigate in detail one of the observed cirrus cloud embedded in a volcanic ash layer. First, the origin of the observed air mass is assigned by calculating ECMWF (European Centre for Medium-Range Weather Forecasts) backward trajectories. With our detailed microphysical box model MAID (Model for Aerosol and Ice Dynamics) (Bunz et al., 2008), we simulate the ice formation along these trajectories. Thus it is possible to distinguish observations from pure volcanic ash, natural cirrus, and induced cirrus clouds. Furthermore, microphysical and optical properties of the resulting ice crystals where investigated with this combination of lidar and model simulations.

In the first two sections, the instrument and methodology is described, starting with the lidar instrument and the measurement technique, followed by a description of the ice model MAID, the calculation of backward trajectories, and their combination with MAID. In Section 3, the observation of the main Eyjafjallajökull volcanic ash cloud and the induced cirrus on 16 April 2010 is presented. The origin of the air masses is analyzed based on trajectory calculations. Subsequently, the IN concentration is estimated from lidar data. The simulation of induced cirrus with MAID, including two sensitivity studies, is described and discussed accordingly.

\section{Instrumentation and methodology}

\subsection{Lidar measurements}

The commercial mobile lidar instrument Leo-Lidar (Leosphere ALS 450) is mostly used for cirrus cloud observation. The laser operates at a wavelength of $355 \mathrm{~nm}$ with a pulse energy of $16 \mathrm{~mJ}$, a pulse duration of $4 \mathrm{~ns}$, and a frequency of $20 \mathrm{~Hz}$. The lidar head including laser and receiver can be tilted, but was zenith pointed during the Eyjfjallajökull ash period. The receiver telescope has a diameter of $15 \mathrm{~cm}$ with around $1.5 \mathrm{mrad}$ field of view reaching full overlap at a range of $510 \mathrm{~m}$. The sampled altitude range is therefore 0.5 to $15 \mathrm{~km}$ with a usual resolution of around $30 \mathrm{~m}$ depending on atmospheric conditions. Two detectors measure the parallel and the perpendicularly polarized backscattered light, respectively. Thus, the depolarization of the scattering particles can be measured. The depolarization is representative of the asphericity of the scattering particles. While cirrus clouds or ash particles mostly create a large signal in the depolarization because of their non-spherical shape, spherical particles create a depolarization close to zero. The volume depolarization is calculated by dividing the perpendicular and parallel signal normalized by constant $\mathrm{C}$ introduced by Schotland et al. (1971). The constant $C$ accounts for differences in the detection efficiency of parallel and perpendicularly polarized light in both detectors. The constant is determined by normalizing the depolarization to an area in the atmosphere where virtually no particle scattering occurs but only the known molecular depolarization. For this study, $\mathrm{C}$ is determined from atmospheric observations before the occurrence of the ash cloud. The particle depolarization is calculated based on the measured volume depolarization and the calculated backscatter coefficient as described in Gross et al. (2012).

Besides the depolarization, also the backscatter and the extinction coefficient are important quantities. The extinction depends on the number, size distribution, and shape of the scattering particles. The extinction is approximately proportional to the concentration and effective particle size of volcanic ash, but also proportional to the ice water content (IWC) of a cirrus cloud. To determine the particle backscatter and extinction coefficient from the backscatter signals by the Fernald - Klett method (Klett, 1981; Fernald, 1984) we have to assume the lidar ratio $\mathrm{L}_{\mathrm{aer}}$. The lidar ratio is defined as the ratio of the particle extinction coefficient and particle backscatter coefficient. It depends strongly on the scattering properties of the measured particles. It is nearly constant within a particle layer with a specific composition, similar shape, and size distribution. During the Eyjafjallajökull eruption, many lidar stations in Europe measured the ash cloud and the lidar ratio with Raman lidar systems. Ansmann et al. (2010) specified a lidar ratio of 55 to $65 \mathrm{sr}$ for a wavelength of $355 \mathrm{~nm}$. Similar values of 50 to $60 \mathrm{sr}$ are found in another study by Gross et al. (2012). We therefore assume a lidar ratio of $60 \mathrm{sr}$ for the conversion of backscatter coefficient into particle extinction in our analysis.

Another uncertainty in the particle extinction is the effect of multiple scattering in clouds or aerosol layers. If the particle effective radius becomes larger the possibility of multiple scattering increases. Through strong forward scattering, single photons remain in the field of view of the detector and again increase the probability of a scattering process. This 
effect leads to an increase of the measured particle backscatter coefficient and an underestimation of the extinction coefficient or optical depth of the atmospheric path. In order to correct the particle extinction profiles for multiple scattering effects we use a fast lidar and radar multiple-scattering model described in Hogan (2008). For extinction profiles with pure ash, an effective radius of $1 \mu \mathrm{m}$ is assumed in the calculations (Gasteiger et al., 2011). For ice crystals and the induced cirrus cloud, the effective radius from model simulation was used and is around $10 \mu \mathrm{m}$. To correct the extinction profile from multiple-scattering model output, the iterative method described in Wandinger (1998) is used. The correction is calculated for atmospheric extinction profiles with low noise. For this purpose, we use at least an average over 12000 single laser pulses measured in a time interval of $10 \mathrm{~min}$ with $150 \mathrm{~m}$ vertical resolution.

\subsection{The kinetic microphysical model MAID}

To investigate the effect of ice formation on volcanic ash particles in the atmosphere, we combined lidar measurements with additional information obtained from microphysical simulations. For the simulations, we have used the kinetic microphysical model MAID (Model for Aerosol and Ice Dynamics) (Bunz et al., 2008). The box model MAID calculates the equilibrium state of trace gas components between the gas phase, ice and aerosol particles. The microphysical ice processes implemented in MAID are as follows: First, heterogeneous freezing after Karcher and Lohmann (2003) with variable numbers of IN in the deposition freezing mode is integrated. In MAID, different heterogeneous freezing thresholds varying with temperature are selectable (Gensch et al., 2008; Krämer and Hildebrandt, 2010), which differ concerning the critical relative humidity with respect to ice. Second, homogeneous freezing after Koop et al. (2000) is included, which allows homogeneous freezing to occur after a heterogeneous freezing event. Further microphysical processes consider the diffusional growth, evaporation, sublimation and Lagrangian ice particle tracking. Sedimentation of ice crystals is now included as a new module in MAID after Spichtinger and Gierens (2009) and Spichtinger and Cziczo (2010) by assuming a sedimentation factor representing the incoming flux of ice particles of the top of the box as a fraction of the outgoing flux at the bottom of the box (cloud top: $0<$ sedimentation factor $<1$ : cloud bottom). The box model is driven by temperature and pressure changes, either artificially generated or realistic atmospheric air parcel trajectories. The crucial parameters for ice formation are set in the model initialization. For this work, the important initialization input parameters are the amount of water vapor as well as the number concentration, the size distribution, and the freezing threshold of the IN.

\subsection{MAID simulations along ECMWF backward trajectories}

In this study, MAID is run along atmospheric air parcel trajectories. For this purpose we used the trajectory module of the Chemical Lagrangian Model for the Stratosphere (CLaMS) (McKenna et al., 2007). Trajectories are calculated using a hybrid vertical coordinate zeta as reported in Konopka et al. (2007) and based on ECMWF analyses data with a vertical resolution of around $600 \mathrm{~m}$ in the altitude range from 7 to $12 \mathrm{~km}$, a horizontal resolution of $1 \times 1 \mathrm{de}-$ gree, and time resolution of $6 \mathrm{~h}$. Trajectories are calculated from the site of the lidar (Jülich) backwards in time and show where the measured air mass originates. Trajectories provide temperature, pressure and humidity on trajectory coordinates, which are necessary for box model simulation.

MAID only works with a constant value of water vapor during the simulation. Therefore the water vapor mixing ratio should be nearly constant along each trajectory. To exclude strong mixing of air masses with different amounts of water vapor, the length of the trajectories is set to smaller values than $48 \mathrm{~h}$ and is therefore less than the typical timescale of air parcel mixing. Additionally trajectories are checked for strong vertical winds or passing convective systems which can imply mixing. Both criteria are fulfilled by the calculated trajectories and are therefore used for MAID simulations.

Moreover ECMWF data often show a dry bias of $\mathrm{H}_{2} \mathrm{O}$ in the upper troposphere (Luo et al., 2008). We checked that the amount of water vapor is consistent with other observational data, e.g. radiosondes. The initialized water vapor is set to the mean mixing ratio along each trajectory. Furthermore, it is verified that the temperature along the trajectory remains below $-35^{\circ} \mathrm{C}$. Above this temperature immersion freezing of water drops, which is not implemented in MAID, could exist in addition to direct ice nucleation by deposition freezing, which is the formation mechanism of cirrus clouds. The microphysical box model is started at the warmest point within each 48 hour trajectory to save computational time and to avoid starting with a supersaturation over ice. Starting the model with a relative humidity above $100 \%$ overestimates the ice production. This also prevents increased uncertainties due to multiple cirrus life cycles (formation and sublimation etc.).

Finally, the ECMWF data are very smooth and do not contain any small-scale temperature fluctuations. Hoyle et al. (2005) showed that these natural fluctuations due to atmospheric wave activity are crucial for the growth of ice crystals and for the resulting ice particle properties (size distribution and ice water content (IWC)). We added a Gaussian distribution of temperature noise with various amplitudes and a typical peak-to-peak fluctuation length of $10 \mathrm{~min}$ to make the trajectory and the model behavior more realistic. The amplitude depends on altitude, geographic latitude and longitude, and is parametrized in a study of Gary (2006). For our study, the fluctuation amplitude is around 0.3 to $0.5^{\circ} \mathrm{C}$. Nevertheless, 

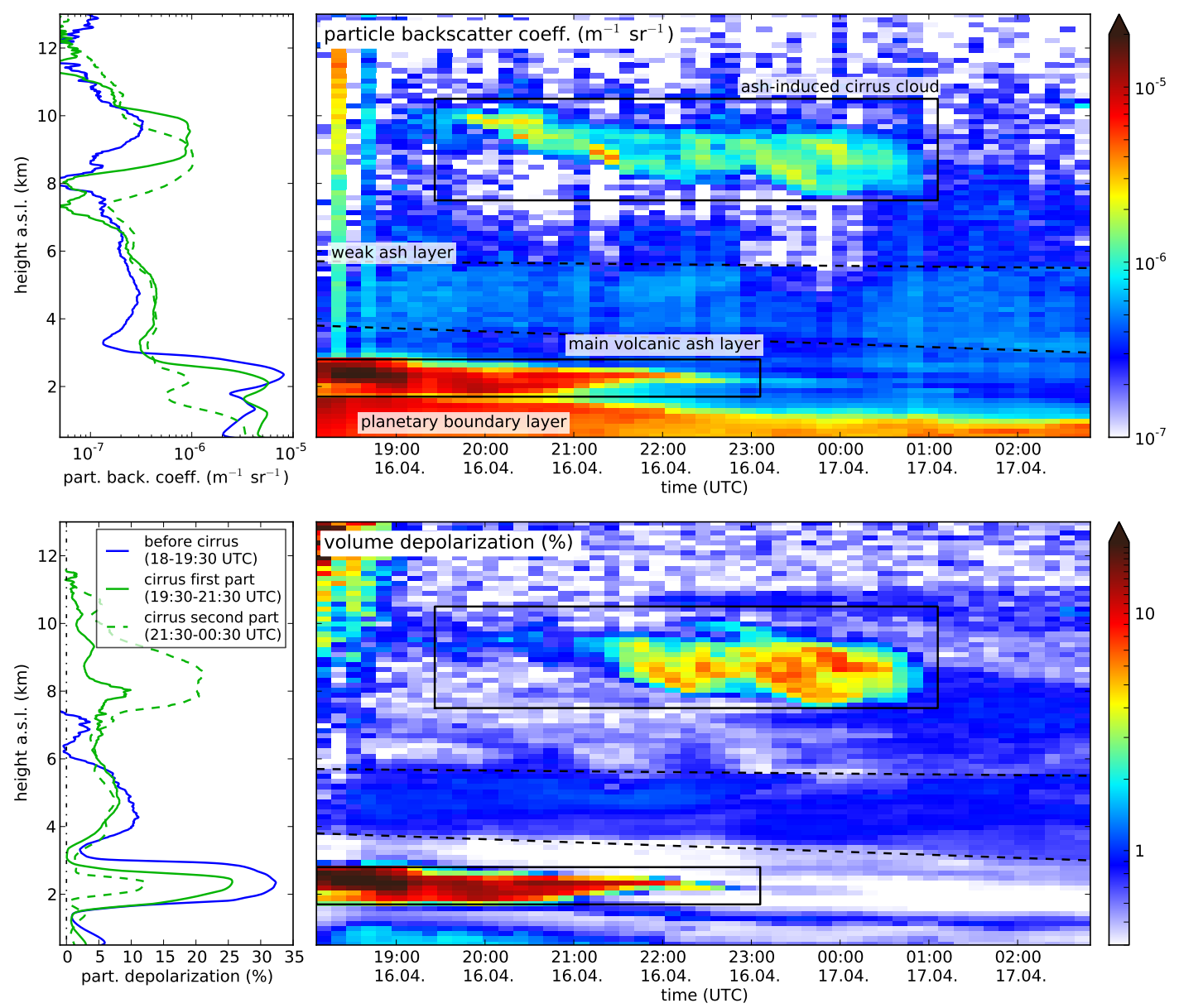

Fig. 1. Particle backscatter coefficient (assuming a lidar ratio of $25 \mathrm{sr}$ ) and volume depolarization measured with backscatter lidar Leo-Lidar on 16-17 April 2010 (18:00-03:00 UTC) averaged over $5 \mathrm{~min}$ of data. Three layers of particles are visible: the main volcanic ash layer between $1.6-3.0 \mathrm{~km}$, a second weak layer in $4-5.5 \mathrm{~km}$, and a layer in the $8-10 \mathrm{~km}$ region, which includes a cirrus cloud. In addition, profiles of backscatter coefficient and particle depolarization are shown in the left panels obtained from averaged data before cirrus occurrence (18:00-19:30 UTC, lidar ratio of $60 \mathrm{sr})$ and two profiles of the first (19:30-21:30 UTC) and second (21:30-00:30 UTC) part of the induced cirrus cloud (lidar ratio $25 \mathrm{sr}$ ).

this Gaussian temperature distribution is arbitrary and generates a random behavior of ice formation. For that reason, we made several model runs for each trajectory, each with newly generated temperature fluctuations. The result of the MAID runs is only considered to be meaningful and robust if more than $50 \%$ of the model runs yield a similar result, i.e. ice particle number concentration and size distribution.

\subsection{Combination of model output and lidar measurments}

The model produces microphysical properties of the cirrus cloud such as ice particle number concentration, size distribution with mass mean radius or effective radius, and IWC. The comparison of the model output with the observations over Jülich is based on the modeled IWC. The IWC is converted into extinction using a parametrization from Heymsfield et al. (2005) derived from extinction and IWC measurements from aircraft in-situ measurements, CloudSat radar, and Calipso lidar data. The parametrization with IWC in $\mathrm{g} \mathrm{m}^{-3}$, extinction $\sigma$ in $\mathrm{m}^{-1}$, and the constants $a$ and $b$ ( $a=119 \mathrm{~g} \mathrm{~m}^{-3}, b=1.22$ ) reads as follows:

$\mathrm{IWC}=a \cdot \sigma^{b}$.

The calculated extinctions can be directly compared to observed extinctions.

\section{The Eyjafjallajökull ash plume}

\subsection{Lidar observation}

Shortly after news of the Eyjafjallajökull eruption and the propagation of a volcanic ash cloud over central Europe on 16 April 2010 we started to operate the lidar at Jülich. And once low-level clouds over Jülich disappeared completely at 
around 18:00 UTC it was possible to observe the volcanic ash up to $10 \mathrm{~km}$. The lidar measurements are shown in Fig. 1 by particle backscatter coefficients derived from five-minute averaged data. Starting from the ground to the top, one can see the planetary boundary layer (PBL) up to $1.6 \mathrm{~km}$ altitude. It is characterized by an increased backscatter coefficient below the main volcanic ash layer (MVL) in the 1.6 to $3 \mathrm{~km}$ altitude range. Both the high backscatter values in the PBL and MVL indicate a high concentration of particles. Mixing of volcanic ash with boundary layer air or sedimentation of larger ash particles has probably taken place and created a high particle loading in the upper part of the boundary layer. High particle depolarization values of $32.5 \%$ are observed in the MVL and are similar found by others with values of 35 to $38 \%$ (Ansmann et al., 2011; Chazette et al., 2012; Gross et al., 2012).

Above this main ash layer, a weaker secondary layer is visible around $4-5.5 \mathrm{~km}$. Above this weak second layer, an apparent third layer with an increased backscatter coefficient exists. This structured layer represents a cirrus cloud embedded in an ash layer (marked as volcanic-ash-induced cirrus). This layer differs from the other ash layers below, with a concurrent increased volume depolarization, which indicates more or larger aspherical particles such as ice crystals. Another aspect also implies the presence of ice crystals. The Klett inversion is either done with forward and backward integration assuming reference heights about 7-7.5 km and 11$12 \mathrm{~km}$, respectively. The Klett inversion with backward integration results in negative backscatter and extinction coefficient if a lidar ratio of $60 \mathrm{sr}$ (pure volcanic ash) is assumed. This lidar ratio indeed suggests the presence of a cirrus cloud instead of pure volcanic ash. Only a lower lidar ratio of $25 \mathrm{sr}$, often found in cirrus, provides realistic results for both Klett solutions. For later considerations, the extinction of the cirrus is determined with this lidar ratio.

Between 19:30 and 21:30, only a weak particle depolarization lower than $5 \%$, but a high backscatter signal is found in cirrus cloud between 8 and $10 \mathrm{~km}$. This is unusual for ice crystals. In comparison, the particle depolarization after $21: 30$ is around $20 \%$. The low volume depolarization in the early phase of observation suggests spherical particles such as droplets. However, liquid water droplets does not exist at temperatures below $-35^{\circ} \mathrm{C}$. But, this behavior is also found by other lidar observations during the Eyjafjallajökull period (Seifert et al., 2011). The most likely reason for this is the occurrence of specular reflection.

In the time period of the occurrence of volcanic ash, the lidar system measured in the zenith orientation. In the case of planar planes of horizontally oriented ice crystals, specular reflection appears (e.g. Westbrook et al., 2010; Sassen and Benson, 2001), which results in a high backscatter coefficient and a low depolarization ratio. Specular reflection occurs under conditions where large planar ice crystals are formed and align horizontally during sedimentation. This is mostly the case for warmer conditions in moist air with tem- peratures between -8 and $-25^{\circ} \mathrm{C}$, where ice crystals can grow to sizes around 50 to $100 \mu \mathrm{m}$ in radius. In the time period between 19:30 and 21:30 the air was mostly cold and relatively dry with temperatures around $-50{ }^{\circ} \mathrm{C}$ and $105 \%$ rel. humidity with respect to ice in the cirrus region (see Sect. 3.2 and Fig. 3). Ice simulation (Sect. 4.1) shows the development of rather small ice crystals around $10 \mu \mathrm{m}$ in radius in a volcanic ash environment. However, the are also observations were specular reflections occurs under colder conditions below $-30^{\circ} \mathrm{C}$ as reported by Noel and Chepfer (2010). Indeed, these observations are very rarely, but indicate that sedimentation of ice crystals can occur under cold conditions producing specular reflection when a zenith pointing lidar is used.

\subsection{Trajectory analysis}

For the observation time between 18:00 to 03:00 UTC, we calculate around 2000 single trajectories in the altitude range between 1 and $12 \mathrm{~km}$. The time interval between two trajectories is $15 \mathrm{~min}$ and the altitude resolution is $200 \mathrm{~m}$. The probability density function (PDF) at each location of all trajectories is shown in Fig. 2a for a latitude/longitude grid with a resolution of $0.2 \times 0.2$ degrees. Since the observed air mass must contain volcanic ash particles to form an induced cirrus, the trajectories have to be close to the Eyjafjallajökull volcano. This is indeed the case as shown in panel a. The figure implies that the most trajectories could contain volcanic ash particles as shown by the lidar observations. In panel $b$, c, and d of Fig. 2 we performed a trajectory analysis to confirm possible ash loadings of air masses and to estimate the possibility of cirrus cloud occurrence. These figures have the same altitude and time scale as the lidar data from Fig. 1, so that it is possible to compare both figures easily. In addition, the range in which the induced cirrus cloud occurred at the observational site is framed by a black box. In panel $b$ the shortest distance to the volcano for each trajectory sampled at Jülich is shown. A layered structure between 2 and $4 \mathrm{~km}$, which has the shortest distances between 0 and $60 \mathrm{~km}$ to the volcano, is clearly visible in panel b. This structure represents the main volcanic ash layer, which is also visible in the lidar data. The second layer in an altitude range from $8-11 \mathrm{~km}$, with distances between 90 and $160 \mathrm{~km}$, can also be identified. This structure coincides with the cirrus observation assumed in Sect. 3.1. Thus the air masses in the region under consideration could potentially contain volcanic ash and the particles could serve as IN. In panel c the transport time from the shortest distance to the lidar site shows the same behavior with the two main layers. Short transportation times of around $24 \mathrm{~h}$ are visible which are in accordance to Dacre et al. (2011). In addition to the IN occurrence, the relative humidity with respect to ice is important for cirrus formation and persistent behavior of the ice crystals. Thus in panel d of Fig. 2 the relative humidity with respect to ice is shown. A blue shaded layer from 8 to $11 \mathrm{~km}$ is clearly visible. This layer shows values slightly above $100 \%$ rel. humidity and in 

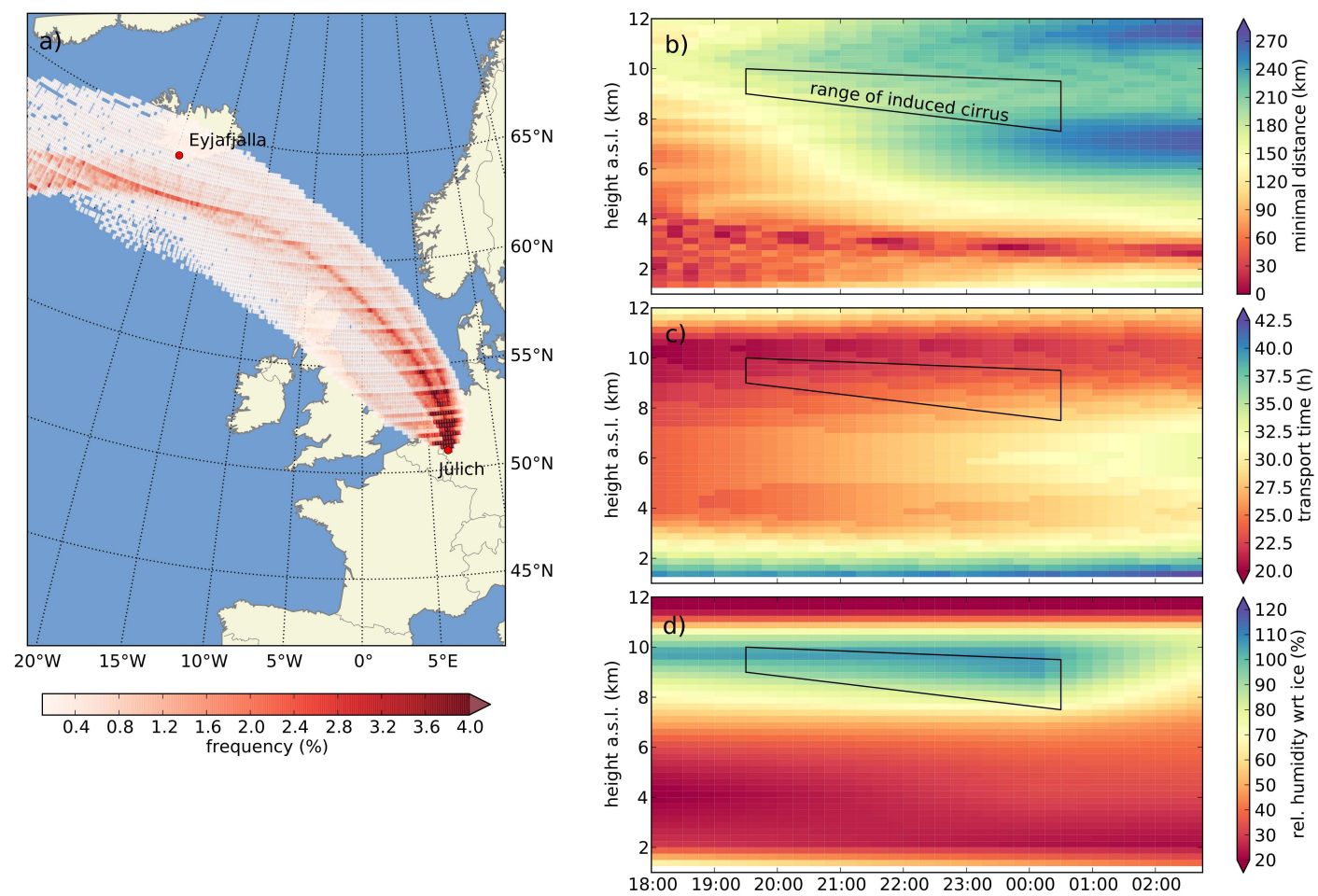

Fig. 2. Backwards trajectories started at a specific time and altitude in Jülich and show where the air mass originates: (a) Probability density function of all calculated trajectories, (b) minimal distance of each trajectory to the Eyjafjallajökull volcano, (c) transportation time from minimal distance, and (d) relative humidity with respect to ice at the end of each trajectory over Jülich.

principle ice crystals can occur in this layer. However, the air masses are only a few percent supersaturated. This implies low freezing thresholds and therefore the existence of very efficient IN in the volcanic ash layer.

Figure 3 shows mean profiles of ECMWF temperature and rel. humidity for three different time intervals (16 April 20:00 UTC; 17 April 00:00 and 01:30 UTC). In addition, one radiosonde launched by DWD (German Meteorological Service) station Essen, $70 \mathrm{~km}$ north west of Jülich at 00:00 UTC on 17 April is shown. The relative humidity data are dry bias corrected with an algorithm provided by Miloshevich et al. (2009). The humidity profiles illustrate a rather good agreement between the ECMWF data and the radiosonde data and rule out the existence of high ice supersaturations. Small discrepancies can be explained by the distance of the launch site from the corresponding ECMWF grid point. Further, the profiles show again that air masses between 8 and $10 \mathrm{~km}$ are only a few percent supersaturated and would suggest no cirrus occurrence under normal clean air conditions. The temperature range from -45 to $-55^{\circ} \mathrm{C}$ between 8 and $10 \mathrm{~km}$ is clearly in the range of possible deposition freezing.

All in all, the trajectories could be used for model simulation of the induced cirrus cloud and the ECMWF data are sufficient for this purpose.

\subsection{IN properties}

Ice formation depends strongly on the ambient conditions of the air mass. Especially the concentration and microphysical properties of aerosol particles, which can serve as IN, have a strong impact on heterogeneous freezing. Both affect also the number concentration of ice crystals and therefore the IWC or the extinction. Thus it is important to know the IN concentration and freezing threshold as precisely as possible to compare the lidar extinction with MAID simulation results in a meaningful manner.

However, the total particle concentration alone could also be estimated from the extinction profile measured with the lidar. The particle concentration can be obtained by applying an extinction to the particle concentration conversion factor. Seifert et al. (2011) used a conversion factor of 0.5 to $1 \times 10^{-6} \mathrm{~m} \mathrm{~cm}^{-3}$, from a study of Ansmann et al. (2008) for Sahara dust particles with radii $>250 \mathrm{~nm}$. Seifert et al. (2011) discussed the fact that the conversion factor for volcanic ash should be similar. Since it is not possible to determine the ash particle concentration during cirrus occurrence, the lidar observations directly before and after the cirrus cloud are used. It is assumed that the ash particle concentration is comparable during cirrus occurrence. The extinction profile derived from averaged data before cirrus occurrence (18:00 to $19: 30$ UTC) and after cirrus occurrence (01:15 to 


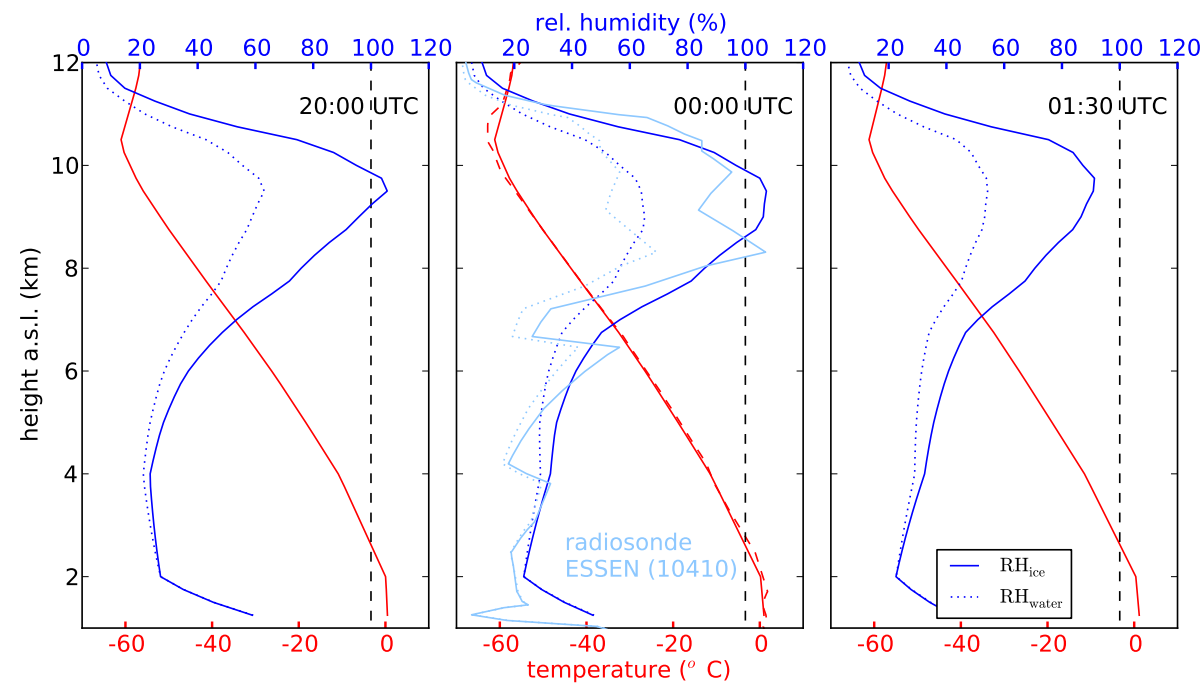

Fig. 3. Profiles of temperature (red lines) and rel. humidity with respect to water $\left(\mathrm{RH}_{\mathrm{water}}\right.$, dotted blue lines) and ice $\left(\mathrm{RH} \mathrm{H}_{\mathrm{ice}}\right.$, solid blue lines) at Jülich from ECMWF data (16 April 2010 at 20:00, and 17 April at 00:00, and 01:30 UTC) and a radiosonde launched in Essen (station code 10410) on 17 April at 00:00 UTC (red dashed line and light blue lines).

03:00 UTC) is shown in Fig. 4 for a lidar ratio of 60 sr. It is further assumed that the air masses observed in these time intervals do not contain ice crystals. This is justified by a low backscatter coefficient and a low volume depolarization visible between 18:00 and 19:30 UTC in the 8 to $10 \mathrm{~km}$ height range in Fig. 1. Figure 4b illustrates the conversion from extinction to particle concentration with a mean conversion factor of $0.75 \times 10^{-6} \mathrm{~m} \mathrm{~cm}^{-3}$ and the range of conversion in the blue shaded area for the profile before cirrus occurrence. The total uncertainty including the uncertainty of extinction and the conversion factor is shown as a reddish shaded area. Ash particle concentrations in the range from 10 to $25 \mathrm{~cm}^{-3}$ are found before cirrus occurrence, while concentrations around $5 \mathrm{~cm}^{-3}$ are found after cirrus occurrence.

Besides the lidar measurements, the most precise measurements of particles can be made with an aircraft probing the ash cloud in situ. During the Ejyafjalla ash period, the German research aircraft DLR Falcon probed the ash cloud on 19 April over Leipzig, Germany (Schumann et al., 2011). In a dive flight pattern a vertical profile of the ash layer is investigated. In an altitude range from 4 to $5.5 \mathrm{~km}$, an ash particle concentration of about $15 \mathrm{~cm}^{-3}$ was found in the size range from 250 to $1000 \mathrm{~nm}$. The concentration of larger particles $>2 \mu \mathrm{m}$ in the same air volume was $0.4 \mathrm{~cm}^{-3}$. Lower concentrations of around $5 \mathrm{~cm}^{-3}$ were found at cirrus altitude during the dive, which is in accordance to lidar observations of Seifert et al. (2011) on 18 April over Leipzig. Although these measurements were taken over Leipzig on 18 and 19 April, these measured concentrations are in good agreement with the estimation from the lidar observations.

However, even a realistic determination of the particle concentration does not directly yield the IN concentration. Steinke et al. (2011) analyzed freezing experiments with Ey- jafjallajökull ash probes in an atmospheric simulation chamber. They found that around $1 \%$ of the ash particles were very efficient IN with freezing thresholds around $110 \%$ rel. humidity with respect to ice at a temperature of $-48^{\circ} \mathrm{C}$ in the deposition freezing mode. Therefore we assume in our analysis that $1 \%$ of the ash particles serve as IN. The IN concentration taking $1 \%$ of the particle concentration before and after cirrus occurrence is also displayed in Fig. $4 \mathrm{~b}$ and c at the top axis. The profile before the cirrus occurrence shows an increased particle concentration from 8 to $11 \mathrm{~km}$ with an IN concentration of $0.12 \mathrm{~cm}^{-3}$ to $0.25 \mathrm{~cm}^{-3}$ in the altitude range of the induced cirrus cloud (marked as a gray shaded area from 8 to $10 \mathrm{~km}$ ). The profile after the cirrus occurrence clearly indicates a lower IN concentration of $0.05 \mathrm{~cm}^{-3}$ in the altitude range of the cirrus cloud. Although the IN concentration above $10 \mathrm{~km}$ stays almost constant in comparison to the profile before cirrus occurrence, the IN concentration increases below $8 \mathrm{~km}$. Obviously, the ash layer descends within the time interval shown in Fig. 4 and leaves the supersaturated region between 8 and $10 \mathrm{~km}$ shown in Fig. 2. The decreasing top height of the cirrus from 10 to $9 \mathrm{~km}$, visible in the temporal progress of the cirrus cloud in the lidar observations (see Fig. 1), confirms the descent of the ash layer. The strong backscatter coefficients in the first part (19:30 to 21:30 UTC) of the cirrus cloud indicates a higher ice particle concentration and therefore a higher IN concentration than the rest of the cirrus cloud. This is in accordance with the estimated concentrations before and after the cirrus occurrence. An IN concentration of $0.10 \mathrm{~cm}^{-3}$ obtained from the mean of both profiles before and after the cirrus occurrence is close to the values found by induced cirrus lidar observation from Seifert et al. (2011). Therefore a suitable assumption for the simulation of the volcanic-ash-induced cirrus is a high IN 


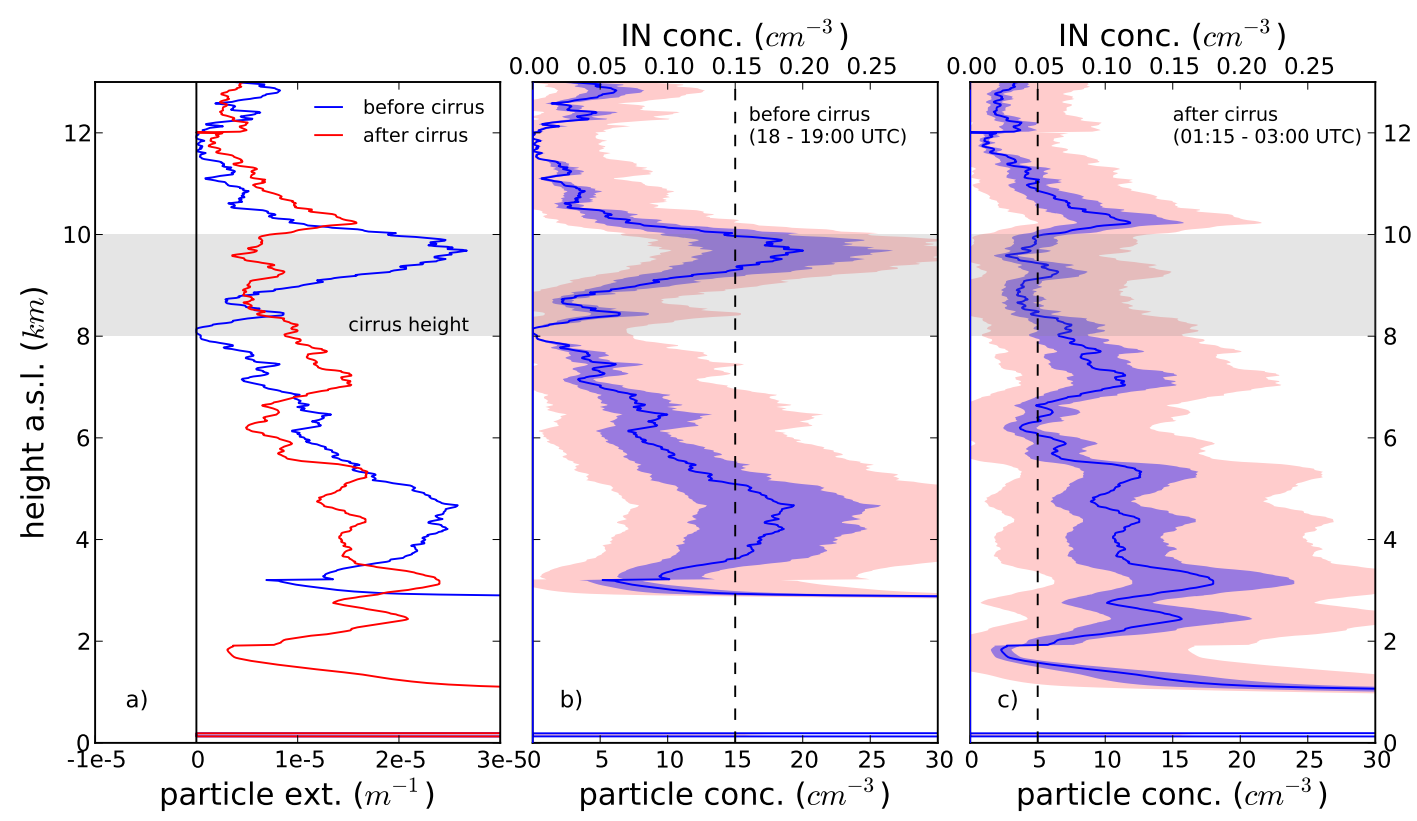

Fig. 4. (a) Lidar extinction profile obtained from averaged data before (blue, 18:00 to 19:30 UTC) the cirrus occurrence and after the cirrus occurrence (red, 01:10 to 03:00 UTC). Corresponding extinctions converted to particle concentration profiles are shown in (b) and (c), respectively. A scale for IN concentration is given at the top of (b) and (c), assuming an IN concentration of $1 \%$ of total particle concentration. Most aerosol structures are caused by a low signal to noise ratio.

concentration of $0.1 \mathrm{~cm}^{-3}$. This IN concentration is around 10 times higher than under normal conditions (DeMott et al., 2010) and implies a modification of the microphysical behavior of ice formation.

Besides the IN concentration, the freezing efficiency or freezing threshold is also important for the simulation of the induced cirrus cloud. Older laboratory studies by Durant et al. (2008) and Fornea et al. (2009) regarded volcanic ash from other volcano eruptions as very efficient IN. Steinke et al. (2011) as well as Seifert et al. (2011) suggest efficient IN during the Eyjafjallajökull ash period. Due to these findings, the assumption of a low freezing threshold for the heterogeneous deposition freezing slightly below $110 \%$ is also justified in general. The freezing threshold is estimated in detail in Sect. 4.1 with the help of a model-based case sensitivity study in comparison to the lidar observation.

Another property used for the ice formation study is the size distribution of volcanic ash. For volcanic ash particles we use a mono modal log-normal distribution with a width of $1.7 \sigma$, minimal radius of $0.1 \mu \mathrm{m}$ and maximum radius of $5 \mu \mathrm{m}$. This values are similar to the outcome of inverted lidar and photometer data from Gasteiger et al. (2011) or aircraft in-situ measurements (Johnson et al., 2012; Schumann et al., 2011).

\section{Eyjafjallajökull ash-induced cirrus}

As described in Sect. 2.2, MAID simulations are performed for each trajectory with the input parameters water vapor, IN concentration, and freezing threshold. The temperature and pressure along the trajectory are taken from ECMWF data. The following two subsections present model sensitivity studies to reproduce and explore the observed cirrus and a comparison between the simulated and the observed cloud.

\subsection{Model sensitivity studies}

\subsubsection{Case study}

The case sensitivity study was performed to determine the set of input parameters which provides the best representation of the cloud extinction measured by the lidar. For this study, 20 representative backward trajectories were used starting at different altitudes and times with a focus on the time period at the beginning of the cirrus occurrence. About 10000 single MAID runs were made with a different sets of input parameters. The parameter space of the initialization covers 7 IN concentrations $\left(0.01,0.03,0.09,0.1,0.2,0.5\right.$, and $\left.1.0 \mathrm{~cm}^{-3}\right)$, 5 freezing thresholds $(105,110,115,120$, and $130 \%$ rel. humidity with respect to ice), and 7 water vapor initializations $(90,100,110,120,130,140$, and 150 in \% of mean ECMWF water vapor along the trajectory). Each trajectory was simulated with two different sets of temperature fluctuations as described in Sect. 2.3. 


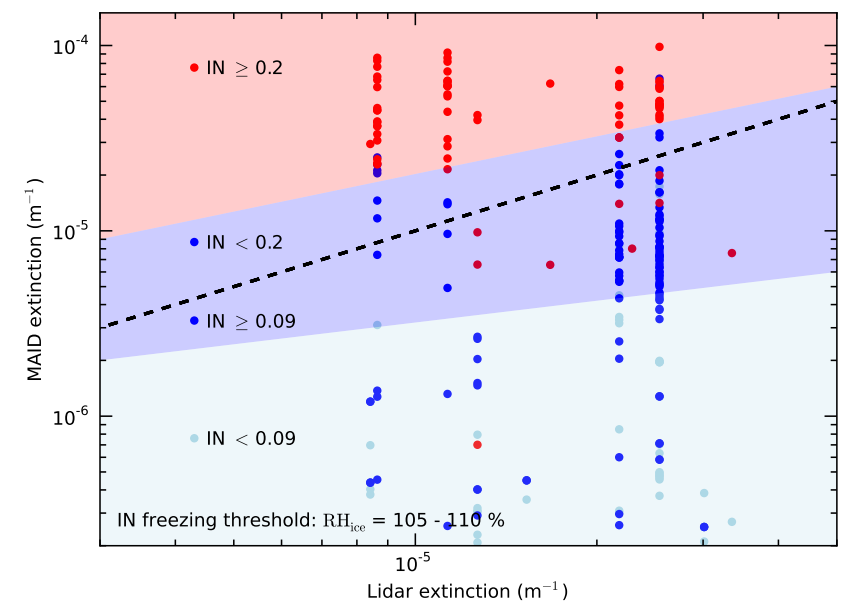

Fig. 5. Scatterplot of observed (lidar) and simulated (MAID) cirrus extinction. For each observed extinction, model simulations with varying IN concentration are performed to find the IN concentration where simulation and observation best matches. Red: high IN concentration $\left(\geq 0.2 \mathrm{~cm}^{-3}\right)$, blue: medium $\left(0.09-0.2 \mathrm{~cm}^{-3}\right)$, light blue: low $\left(<0.09 \mathrm{~cm}^{-3}\right)$. The black dashed curve represents the $1: 1$ line between lidar and MAID extinction. The freezing threshold of the IN is set to $105-110 \% \mathrm{RH}_{\text {ice }}$.

In none of the model runs homogeneous freezing occurred after the heterogeneous freezing event even with the superimposed temperature fluctuations. These fluctuations seemingly play only a minor role in the ice crystal formation process at low cooling rates and high loading of effective IN.

The results of all model runs were compared with the lidar extinction by calculating the extinction based on the IWC as explained in Sect. 2.4. The best agreement with the lidar observation is obtained for the parameter sets with high IN concentrations of $0.09-0.2 \mathrm{~cm}^{-3}$, a freezing threshold around 105 to $110 \%$, and with a water initialization of $100 \%$ ECMWF water vapor.

Figure 5 illustrates the influence of IN concentration relating to the extinction. Both MAID and lidar extinctions are plotted against each other. Only trajectories with volcanic ash conditions, low freezing threshold in the range of 105-110\% rel. humidity and water vapor less than $110 \%$ from ECMWF are considered. Most of trajectories produce ice crystals independent of the IN concentration. However, the resulting extinction strongly depends on the number of IN as can be seen in Fig. 5 (red dots): if the model is initialized with high IN concentration more ice crystals can be formed resulting in a higher extinction signal than the observation. Analogously, a low IN concentration results in fewer ice crystals and a low extinction (light blue dots in light bluish area). In addition, a small IN concentration results in larger ice crystals that can sediment out before reaching the site of observation. As shown in Fig. 5, the best agreement between MAID and lidar extinction is found for a range of IN concentration from 0.09 to $0.2 \mathrm{~cm}^{-3}$. This fits well with the estimated concentration

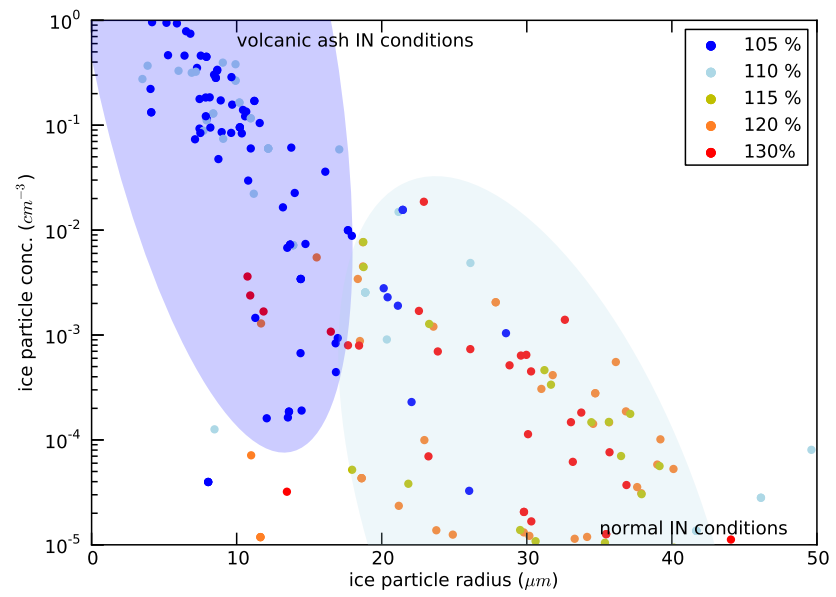

Fig. 6. MAID simulations of ice particle concentrations and corresponding size for various IN concentrations. Under volcanic ash IN conditions (blue shaded area) with a IN concentration above $0.1 \mathrm{~cm}^{-3}$ and a freezing threshold of 105 to $110 \%$ (blueish dots) more but smaller ice crystals appear than under normal IN conditions (light blue shaded area) with a IN concentration below $0.09 \mathrm{~cm}^{-3}$ and a freezing threshold higher than $110 \%$ (yellowreddish dots).

from the lidar observation before the cirrus cloud derived in Sect. 3.3, which was of the order of 0.1 to $0.2 \mathrm{~cm}^{-3}$. The lidar observations after the cirrus occurrence are compatible with somewhat lower IN numbers (down to $0.05 \mathrm{~cm}^{-3}$ ) and suggest some variation of IN concentration over time.

During the Eyjafjallajökull ash period, the air in the cirrus region was mostly relatively dry (see Sect. 3.2 and Seifert et al., 2011) and at most only a few percent supersaturated. Ice formation only occurred in the presence of very effective IN (e.g. volcanic ash), allowing a low freezing threshold below $110 \%$. Trajectories show that ice formation also occurs with higher water vapor initialization above $110 \%$ of the ECMWF mean value. However in fact the ECMWF data agree well with the radiosonde profile in Fig. 3 and Seifert et al. (2011) show similar humidity profiles over Lindenberg and Meiningen, Germany. ECMWF water vapor is thus suitable for the model initialization and can reproduce ice formation in the volcanic ash environment in accordance with the lidar observations. Under these circumstances, a cirrus cloud was only formed under volcanic ash conditions.

The possible impact of volcanic ash on cirrus microphysical properties is shown in Fig. 6 where model results of ice particle numbers and sizes for various IN concentrations and freezing thresholds (see color code in Fig. 6) are plotted. The results of the model runs can be split up into two regimes denoted as normal and volcanic ash IN conditions. Under volcanic ash IN conditions (blue shaded area) with a freezing threshold of 105 to $110 \%$ (blueish dots) more but smaller $\left(\mathrm{R}_{\text {ice }} \sim 10 \mu \mathrm{m}\right)$ ice crystals appear than under normal IN conditions (light blue shaded area, $R_{\text {ice }}=20-40 \mu \mathrm{m}$ ) with 


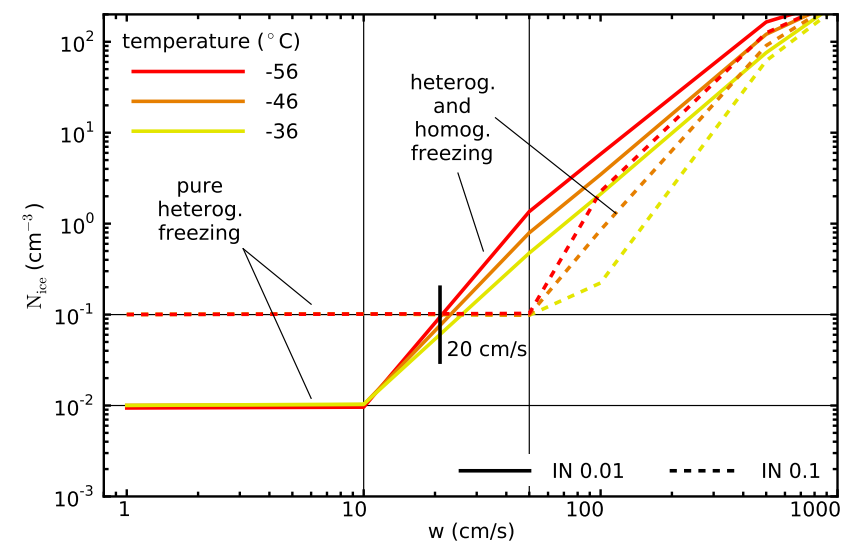

Fig. 7. Ice crystal numbers vs. vertical velocity $\mathrm{w}\left(\mathrm{cm} \mathrm{s}^{-1}\right)$ from idealized MAID sensitivity runs for normal and strong polluted IN conditions (IN number 0.01 and $0.1 \mathrm{~cm}^{-3}$ ) and three temperatures. The freezing threshold is at $\mathrm{RH}_{\text {ice }}=110 \%$. Note that the ice crystal numbers are identical in case of a higher freezing threshold, but that the formation temperature (indicated in the legend) would be lower. For more detail see text.

a freezing threshold higher than $110 \%$ (yellow-reddish dots). This implies that a high loading of volcanic ash can alter the microphysical and thus radiative properties of cirrus such that instead of a cloud with few large crystals a cloud having many small crystals forms. Moreover, it can happen that the presence of volcanic ash even allows a cirrus cloud to form.

\subsubsection{Idealized simulations}

For a more general view on the change of cirrus properties with the concentration of efficient IN, we compared in another set of idealized MAID sensitivity runs the number of ice crystals appearing from heterogeneous ice nucleation (with possible subsequent homogeneous freezing) for normal and polluted IN conditions. In Fig. 7, the ice crystal numbers nucleated for vertical velocities ( $\mathrm{w}$ in $\mathrm{cm} \mathrm{s}^{-1}$ ) ranging from $1 \mathrm{~cm} \mathrm{~s}^{-1}$ up to $10 \mathrm{~m} \mathrm{~s}^{-1}$ are shown for temperatures varying between about $-60{ }^{\circ} \mathrm{C}$ and $-35^{\circ} \mathrm{C}$, i.e. the mid-latitude cirrus range is covered by these sensitivity runs. Here, MAID is driven by constant vertical velocities (i.e. constant temperature and corresponding pressure changes) and is initialized with an amount of water corresponding to $\mathrm{RH}_{\text {ice }}=90 \%$. Small scale temperature fluctuations are not superimposed in these simulations since from the case study it became obvious that these fluctuations do not trigger a second homogeneous freezing event. Figure 7 shows the results for IN concentrations of $0.01 \mathrm{~cm}^{-3}$ (normal conditions) and $0.1 \mathrm{~cm}^{-3}$ (polluted conditions), which corresponds to the observed volcanic ash induced IN number. The resulting ice particle numbers in the idealized model runs are quite similar to former studies of Kärcher et al. (2006), Gierens (2003), and Spichtinger and Cziczo (2010).
Under normal conditions the ice crystal numbers are identical to the IN number (pure heterogeneous freezing) for small vertical velocities below $10 \mathrm{~cm} \mathrm{~s}^{-1}$ and for all temperatures (Fig. 7, solid lines). That means that the updraft is not strong enough to raise $\mathrm{RH}_{\text {ice }}$ up to the homogeneous freezing threshold after the heterogeneous ice nucleation event. Note that in these cases homogeneous freezing would produce fewer ice crystal than the heterogeneous. For higher vertical velocities, the ice crystal numbers increase due to a second homogeneous freezing event, producing more ice crystals the higher the vertical velocity and the colder the temperature is, as expected for the homogeneous freezing process.

The high amount of IN in the polluted case also leads to an identical ice crystal number, but up to vertical velocities of about $50 \mathrm{~cm} \mathrm{~s}^{-1}$ (Fig. 7, dotted lines). This is since the many ice crystals can deplete the water vapor more efficiently and thus stronger updrafts are necessary to increase $\mathrm{RH}_{\text {ice }}$ up to the homogeneous freezing threshold. For higher vertical velocities the same behavior as in the normal case is seen, but with slightly lower ice crystal numbers.

Comparing the two scenarios it can be seen that for updrafts smaller than about $20 \mathrm{~cm} \mathrm{~s}^{-1}$ the microphysical properties of cirrus clouds are generally influenced by a high loading of IN in the way we observed it in our volcanic ash case study, namely that cirrus with more - but smaller - ice crystals appear. For higher vertical velocities the picture reverses: now the ice crystal numbers in the polluted cirrus are smaller than those of the normal cirrus, but approaching to each other with increasing updraft. For comparison, the large scale vertical updrafts in the case of the ash-induced cirrus were rather small with values around $1 \mathrm{~cm} \mathrm{~s}^{-1}$ and a standard deviation of around $0.5 \mathrm{~cm} \mathrm{~s}^{-1}$. In summary it can be seen that cirrus clouds can be modified by a high number of heterogeneously freezing efficient IN over nearly the complete atmospheric updraft range.

\subsection{Comparison of the observed cirrus cloud with model simulations}

The case sensitivity study, described in the previous section, shows that volcanic ash particles are necessary to reproduce the observed extinction or cirrus cloud. An interesting question is whether the whole cloud can be reproduced by the model and ECMWF data. To answer this question we calculated backward trajectories from 18:00 to 03:00 UTC with $15 \mathrm{~min}$ time and $200 \mathrm{~m}$ vertical resolution. To capture the whole height range of the cirrus and ash occurrence the trajectories are calculated from 7 to $11 \mathrm{~km}$. Again five different sets of temperature fluctuations are used for each trajectory to account for temperature variability not captured by ECMWF. A total of 3600 single MAID runs results in a 2$\mathrm{D}$ picture of the cloud that can be compared with the lidar observation. The model runs are initialized as follows. The amount of water vapor is set to $100 \%$ of ECMWF in all 

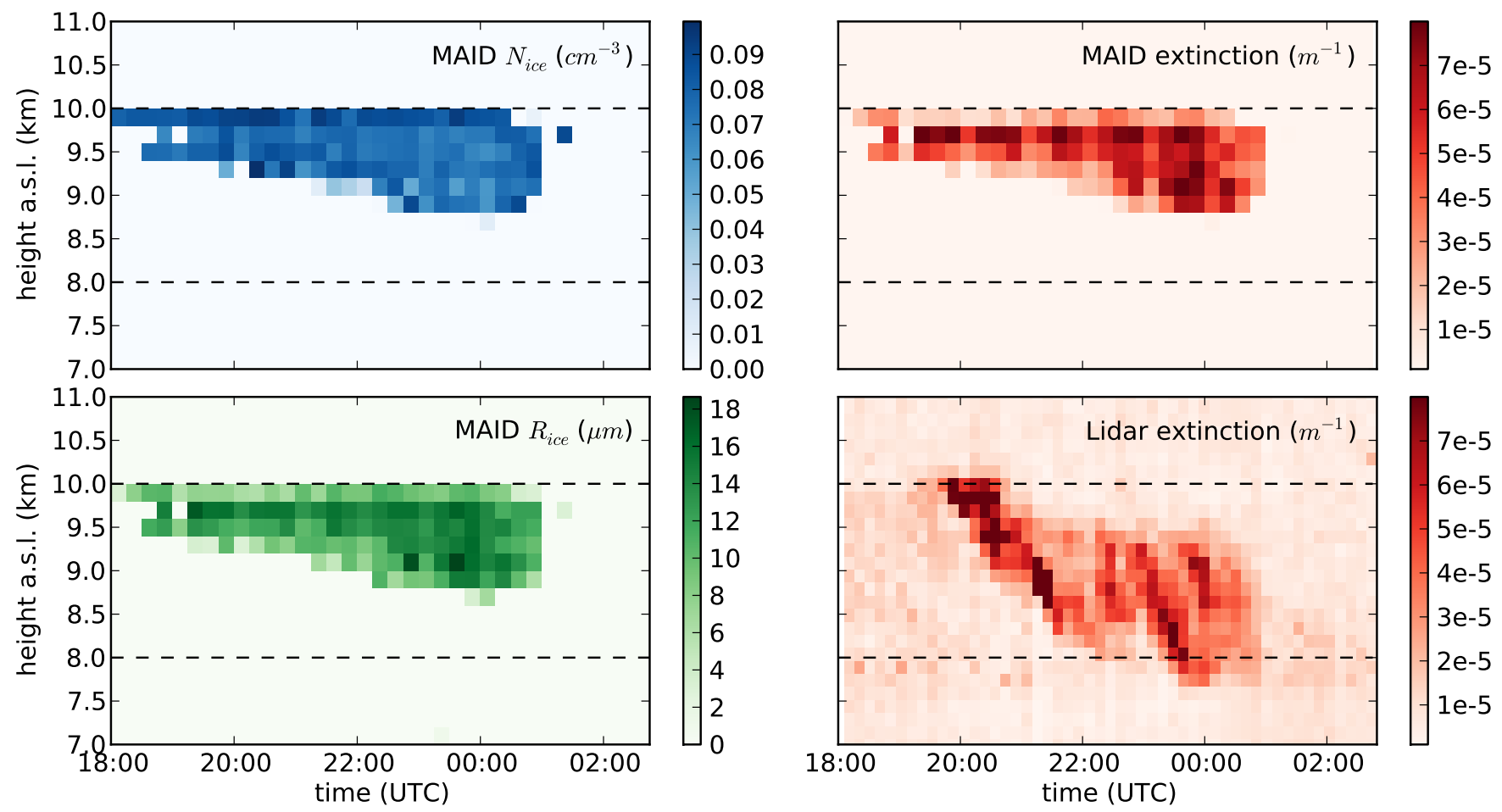

Fig. 8. Comparison of MAID simulated and observed induced cirrus cloud. Ice number concentration $\left(\mathrm{N}_{\mathrm{ice}}\right)$, mean radius $\left(\mathrm{R}_{\mathrm{ice}}\right)$, calculated extinction of MAID runs are shown as well as lidar-determined extinction.

trajectories in accordance with the results from the sensitivity study. We assume a slight sedimentation of ice crystals (sedimentation factor of 0.9) which is common for all trajectories in the middle of a cirrus cloud. In altitude ranges between 8 and $10 \mathrm{~km}$, the IN properties are set to a concentration of $0.1 \mathrm{~cm}^{-3}$ with a low freezing threshold around $105 \%$ rel. humidity with respect to ice. Above and below, a smaller concentration of $0.01 \mathrm{~cm}^{-3}$ and a higher freezing threshold around $130 \%$ rel. humidity is assumed to represent the normal IN conditions. These rough assumptions are consistent with the lidar-determined ash profile before cirrus occurrence.

The result is illustrated in Fig. 8. On the left side, the microphysical properties of ice crystals, number concentration and mean radius are shown. The right side displays the extinction determined from the simulation and lidar observation. A reasonable correspondence between the extinction simulated by MAID and the observed values is found. The occurrence of the simulated cloud is around one hour too early, but disappeared almost on time at 01:00 UTC. The top height is limited through the IN properties of the trajectories. Thus it fits well at the beginning and overestimates the height after about 21:00 UTC. The cloud base height is overestimated almost all the time. The observed cirrus base height goes down to $8 \mathrm{~km}$ while the lower limit of simulated cirrus is around $8.8 \mathrm{~km}$. This is an effect of underlying ECMWF trajectories, which are too dry to contain ice crystals below
$8.8 \mathrm{~km}$ see Fig. 2). The ice crystals present would sublimate within a few minutes. Again the size of the resulting ice crystals is mostly around 10 to $15 \mu \mathrm{m}$ and this is rather small in comparison to observations of natural cirrus clouds from purely heterogeneous freezing under normal conditions. The number concentration is around 0.07 to $0.09 \mathrm{~cm}^{-3}$ and lower than the initialization of $0.1 \mathrm{IN}$ per $\mathrm{cm}^{-3}$. This implies that sedimentation along the trajectory has a significant effect despite the small sizes of the ice crystals. This is due to the long cirrus occurrence of several hours within the trajectories and thus also permitting sufficient time for a slow sedimentation. The standard deviation of resulting ice particle number in the different trajectory realizations is in most cases in the order of 1 to $10 \%$. This also corroborate the use of only two representation in the case study above. Overall, it is obvious that our simplified model runs provide a reasonable reproduction of the observed cirrus extinction structure. It is shown further that the influence of volcanic ash as IN could be simulated with the box model MAID.

\section{Conclusions}

This study investigates heterogeneous ice formation by Eyjafjallajökull volcanic ash particles based on a lidar observation over Jülich on 16 April combined with box model simulations. The observed cirrus cloud could be qualitatively reproduced based on ECMWF trajectories with a mean 
concentration of $0.08 \mathrm{~cm}^{-3}$ and mean radius of $12 \mu \mathrm{m}$. The IN concentration determined by lidar measurements and a model sensitivity study implies an IN concentration of around $0.1 \mathrm{~cm}^{-3}$ at the beginning of cloud occurrence. Differences between the observed and simulated induced cirrus cloud can most likely be attributed to missing small-scale fluctuations in the ECMWF meteorological fields and uncertainties in the IN concentration during cirrus occurrence. In our simulations, the induced cirrus cloud occurred only with the presence of very effective volcanic ash ice nuclei having a freezing threshold of around $105 \%$ rel. humidity with respect to ice. This effectiveness of heterogeneous ice formation is in accordance with laboratory studies. The simulation results in rather small but many ice crystals. This means that the microphysical properties of the observed cloud are significantly influenced by the high ash loading. From a set of idealized model sensitivity runs it is shown that this effect is general for updrafts up to $50 \mathrm{~cm} \mathrm{~s}^{-1}$ and thus is crucial for the simulation and prediction of cirrus clouds in an environment polluted by very efficient IN (e.g. volcanic ash).

Acknowledgements. The commercial lidar instrument was manufactured by Leosphere under type designation ALS 450. We wish to thank Leosphere for good cooperation and support. Furthermore, we thanks the Department of Atmospheric Science at the University of Wyoming for providing the radiosonde data (http://weather.uwyo.edu/upperair/sounding.html). Sincere thanks to the whole CLaMS team and in particular to Jens-Uwe Grooß for supporting the trajectory calculations. In addition, we acknowledge the European Centre for Medium-Range Weather Forecasts for meteorological reanalysis data support. Thanks to J. Carter-Sigglow from the language service of Forschungszentrum Jülich for language revision. Here, we would like to express our deep grief for our dear colleague Cornelius Schiller, who passed away on 3 March 2012.

The service charges for this open access publication have been covered by a Research Centre of the Helmholtz Association.

Edited by: D. J. Cziczo

\section{References}

Ansmann, A., Tesche, M., Althausen, D., Mueller, D., Seifert, P., Freudenthaler, V., Heese, B., Wiegner, M., Pisani, G., Knippertz, P., and Dubovik, O.: Influence of Saharan dust on cloud glaciation in southern Morocco during the Saharan Mineral Dust Experiment, J. Geophys. Res.-Atmos., 113, D04210, doi:10.1029/2007JD008785, 2008.

Ansmann, A., Tesche, M., Gross, S., Freudenthaler, V., Seifert, P., Hiebsch, A., Schmidt, J., Wandinger, U., Mattis, I., Muller, D., and Wiegner, M.: The 16 April 2010 major volcanic ash plume over central Europe: EARLINET lidar and AERONET photometer observations at Leipzig and Munich, Germany, Geophys. Res. Lett., 37, L13810, doi:10.1029/2010GL043809, 2010.
Ansmann, A., Tesche, M., Seifert, P., Gross, S., Freudenthaler, V., Apituley, A., Wilson, K. M., Serikov, I., Linne, H., Heinold, B., Hiebsch, A., Schnell, F., Schmidt, J., Mattis, I., Wandinger, U., and Wiegner, M.: Ash and fine-mode particle mass profiles from EARLINET-AERONET observations over central Europe after the eruptions of the Eyjafjallajokull volcano in 2010, J. Geophys. Res.-Atmos., 116, D00U02, doi:10.1029/2010JD015567, 2011.

Bingemer, H., Klein, H., Ebert, M., Haunold, W., Bundke, U., Herrmann, T., Kandler, K., Müller-Ebert, D., Weinbruch, S., Judt, A., Wéber, A., Nillius, B., Ardon-Dryer, K., Levin, Z., and Curtius, J.: Atmospheric ice nuclei in the Eyjafjallajökull volcanic ash plume, Atmos. Chem. Phys., 12, 857-867, doi:10.5194/acp12-857-2012, 2012.

Bunz, H., Benz, S., Gensch, I., and Kraemer, M.: MAID: a model to simulate UT/LS aerosols and ice clouds, Environ. Res. Lett., 3, 035001, doi:10.1088/1748-9326/3/3/035001, 2008.

Chazette, P., Bocquet, M., Royer, P., Winiarek, V., Raut, J.C., Labazuy, P., Gouhier, M., Lardier, M., and Cariou, J.P.: Eyjafjallajkull ash concentrations derived from both lidar and modeling, J. Geophys. Res.-Atmos., 117, D00U14, doi:10.1029/2011JD015755, 2012.

Dacre, H. F., Grant, A. L. M., Hogan, R. J., Belcher, S. E., Thomson, D. J., Devenish, B. J., Marenco, F., Hort, M. C., Haywood, J. M., Ansmann, A., Mattis, I., and Clarisse, L.: Evaluating the structure and magnitude of the ash plume during the initial phase of the 2010 Eyjafjallajokull eruption using lidar observations and NAME simulations, J. Geophys. Res.-Atmos., 116, D00U03, doi:10.1029/2011JD015608, 2011.

DeMott, P. J., Prenni, A. J., Liu, X., Kreidenweis, S. M., Petters, M. D., Twohy, C. H., Richardson, M. S., Eidhammer, T., and Rogers, D. C.: Predicting global atmospheric ice nuclei distributions and their impacts on climate, Proc. Natl. Acad. Sci. USA, 107, 11217-11222, doi:10.1073/pnas.0910818107, 2010.

Durant, A. J., Shaw, R. A., Rose, W. I., Mi, Y., and Ernst, G. G. J.: Ice nucleation and overseeding of ice in volcanic clouds, J. Geophys. Res.-Atmos., 113, D09206, doi:10.1029/2007JD009064, 2008.

Fernald, F. G.: Analysis of Atmospheric Lidar Observations - Some Comments, Appl. Optics, 23, 652-653, 1984.

Fornea, A. P., Brooks, S. D., Dooley, J. B., and Saha, A.: Heterogeneous freezing of ice on atmospheric aerosols containing ash, soot, and soil, J. Geophys. Res.-Atmos., 114, D13201, doi:10.1029/2009JD011958, 2009.

Gary, B. L.: Mesoscale temperature fluctuations in the stratosphere, Atmos. Chem. Phys., 6, 4577-4589, doi:10.5194/acp-6-45772006, 2006.

Gasteiger, J., Gross, S., Freudenthaler, V., and Wiegner, M.: Volcanic ash from Iceland over Munich: mass concentration retrieved from ground-based remote sensing measurements, Atmos. Chem. Phys., 11, 2209-2223, doi:10.5194/acp-11-22092011, 2011.

Gensch, I. V., Bunz, H., Baumgardner, D. G., Christensen, L. E., Fahey, D. W., Herman, R. L., Popp, P. J., Smith, J. B., Troy, R. F., Webster, C. R., Weinstock, E. M., Wilson, J. C., Peter, T., and Kraemer, M.: Supersaturations, microphysics and nitric acid partitioning in a cold cirrus cloud observed during CR-AVE 2006: an observation-modelling intercomparison study, Environ. Res. Lett., 3, 035003, doi:10.1088/1748-9326/3/3/035003, 2008. 
Gierens, K.: On the transition between heterogeneous and homogeneous freezing, Atmos. Chem. Phys., 3, 437-446, doi:10.5194/acp-3-437-2003, 2003.

Gross, S., Freudenthaler, V., Wiegner, M., Gasteiger, J., Geiss, A., and Schnell, F.: Dual-wavelength linear depolarization ratio of volcanic aerosols: Lidar measurements of the Eyjafjallajokull plume over Maisach, Germany, Atmos Environ., 48, 8596, doi:10.1016/j.atmosenv.2011.06.017, 2012.

Heymsfield, A. J., Winker, D., and van Zadelhoff, G. J.: Extinctionice water content-effective radius algorithms for CALIPSO, Geophys. Res. Lett., 32, L10807, doi:10.1029/2005GL022742, 2005.

Hogan, R. J.: Fast Lidar and Radar Multiple-Scattering Models. Part I: Small-Angle Scattering Using the Photon Variance-Covariance Method, J. Atmos. Sci., 65, 3621-3635, doi:10.1175/2008JAS2642.1, 2008.

Hoyle, C., Luo, B., and Peter, T.: The Origin of High Ice Crystal Number Densities in Cirrus Clouds, J. Atmos. Sci., 62, 25682579, 2005.

Hoyle, C. R., Pinti, V., Welti, A., Zobrist, B., Marcolli, C., Luo, B., Hoeskuldsson, A., Mattsson, H. B., Stetzer, O., Thorsteinsson, T., Larsen, G., and Peter, T.: Ice nucleation properties of volcanic ash from Eyjafjallajökull, Atmos. Chem. Phys., 11, 9911-9926, doi:10.5194/acp-11-9911-2011, 2011.

Isono, K., Komabayasi, M., and Ono, A.: Volcanoes As A Source of Atmospheric Ice Nuclei, Nature, 183, 317-318, doi:10.1038/183317a0, 1959.

Johnson, B., Turnbull, K., Brown, P., Burgess, R., Dorsey, J., Baran, A. J., Webster, H., Haywood, J., Cotton, R., Ulanowski, Z., Hesse, E., Woolley, A., and Rosenberg, P.: In situ observations of volcanic ash clouds from the FAAM aircraft during the eruption of Eyjafjallajokull in 2010, J. Geophys. Res.-Atmos., 117, D00U24, doi:10.1029/2011JD016760, 2012.

Karcher, B. and Lohmann, U.: A parameterization of cirrus cloud formation: Heterogeneous freezing, J. Geophys. Res.-Atmos., 108, 4402, doi:10.1029/2002JD003220, 2003.

Kärcher, B., Hendricks, J., and Lohmann, U.: Physically based parameterization of cirrus cloud formation for use in global atmospheric models, J. Geophys. Res., 111, D01205, doi:10.1029/2005JD006219, 2006.

Klett, J. D.: Stable Analytical Inversion Solution For Processing Lidar Returns, Applied Optics, 20, 211-220, doi:10.1364/AO.20.000211, 1981.

Konopka, P., Guenther, G., Mueller, R., dos Santos, F. H. S., Schiller, C., Ravegnani, F., Ulanovsky, A., Schlager, H., Volk, C. M., Viciani, S., Pan, L. L., McKenna, D. . S., and Riese, M.: Contribution of mixing to upward transport across the tropical tropopause layer (TTL), Atmos. Chem. Phys., 7, 3285-3308, doi:10.5194/acp-7-3285-2007, 2007.

Koop, T., Luo, B., Tsias, A., and Peter, T.: Water activity as the determinant for homogeneous ice nucleation in aqueous solutions, Nature, 406, 611-614, 2000.

Krämer, M. and Hildebrandt, M.: The role of heterogeneous freezing in cirrus formation: new model sensitivity studies, AMS Cloud Physics Conference, Portland, USA, 2010.

Langer, G., Garcia, C. J., Mendonca, B. G., Pueschel, R. F., and Fullerto.CM: Hawaiian Volcanos - Source of Ice Nuclei, J. Geophys. Res., 79, 873-875, doi:10.1029/JC079i006p00873, 1974.

Luo, Z. Z., Kley, D., Johnson, R. H., and Smit, H.: Ten years of measurements of tropical upper-tropospheric water vapor by
MOZAIC. Part II: Assessing the ECMWF humidity analysis, J. Climate, 21, 1449-1466, doi:10.1175/2007JCLI1887.1, 2008.

McKenna, D. S., Konopka, P., Grooss, J. U., Gunther, G., Muller, R., Spang, R., Offermann, D., and Orsolini, Y.: A new Chemical Lagrangian Model of the Stratosphere (CLaMS) - 1. Formulation of advection and mixing, J. Geophys. Res.-Atmos., 107, 4309, doi:10.1029/2000JD000114, 2007.

Miloshevich, L. M., Vomel, H., Whiteman, D. N., and Leblanc, T.: Accuracy assessment and correction of Vaisala RS92 radiosonde water vapor measurements, J. Geophys. Res.-Atmos., 114, D11305, doi:10.1029/2008JD011565, 2009.

Noel, V. and Chepfer, H.: A global view of horizontally oriented crystals in ice clouds from Cloud-Aerosol Lidar and Infrared Pathfinder Satellite Observation (CALIPSO), J. Geophys. Res.Atmos., 115, D00H23, doi:10.1029/2009JD012365, 2010.

Prenni, A. J., Demott, P. J., Rogers, D. C., Kreidenweis, S. M., Mcfarquhar, G. M., Zhang, G., and Poellot, M. R.: Ice nuclei characteristics from M-PACE and their relation to ice formation in clouds, Tellus B, 61, 436-448, doi:10.1111/j.16000889.2009.00415.x, 2009.

Sassen, K. and Benson, S.: A midlatitude cirrus cloud climatology from the facility for atmospheric remote sensing. Part II: Microphysical properties derived from lidar depolarization, Journal of the Atmospheric Sciences, 58, 2103-2112, doi:10.1175/15200469(2001)058<2103:AMCCCF>2.0.CO;2, 2001.

Schnell, R. C. and Delany, A. C.: Airborne Ice Nuclei Near An Active Volcano, Nature, 264, 535-536, doi:10.1038/264535a0, 1976.

Schotland, R. M., Sassen, K., and Stone, R.: Observations by Lidar of Linear Depolarization Ratios for Hydrometeors, Journal of Applied Meteorology, 10, 1011-1017, doi:10.1175/15200450(1971)010<1011:OBLOLD>2.0.CO;2, 1971.

Schumann, U., Weinzierl, B., Reitebuch, O., Schlager, H., Minikin, A., Forster, C., Baumann, R., Sailer, T., Graf, K., Mannstein, H., Voigt, C., Rahm, S., Simmet, R., Scheibe, M., Lichtenstern, M., Stock, P., Ruba, H., Schauble, D., Tafferner, A., Rautenhaus, M., Gerz, T., Ziereis, H., Krautstrunk, M., Mallaun, C., Gayet, J. F., Lieke, K., Kandler, K., Ebert, M., Weinbruch, S., Stohl, A., Gasteiger, J., Gross, S., Freudenthaler, V., Wiegner, M., Ansmann, A., Tesche, M., Olafsson, H., and Sturm, K.: Airborne observations of the Eyjafjalla volcano ash cloud over Europe during air space closure in April and May 2010, Atmos. Chem. Phys., 11, 2245-2279, doi:10.5194/acp-11-2245-2011, 2011.

Seifert, P., Ansmann, A., Gross, S., Freudenthaler, V., Heinold, B., Hiebsch, A., Mattis, I., Schmidt, J., Schnell, F., Tesche, M., Wandinger, U., and Wiegner, M.: Ice formation in ashinfluenced clouds after the eruption of the Eyjafjallajokull volcano in April 2010, J. Geophys. Res.-Atmos., 116, D00U04, doi:10.1029/2011JD015702, 2011.

Spichtinger, P. and Cziczo, D. J.: Impact of heterogeneous ice nuclei on homogeneous freezing events in cirrus clouds, J. Geophys. Res.-Atmos., 115, D14208, doi:10.1029/2009JD012168, 2010.

Spichtinger, P. and Gierens, K.: Modelling Cirrus Clouds. Part 1a: Model description and validation, Atmos. Chem. Phys., 9, 685706, doi:10.5194/acp-9-685-2009, 2009.

Steinke, I., Möhler, O., Kiselev, A., Niemand, M., Saathoff, H., Schnaiter, M., Skrotzki, J., Hoose, C., and Leisner, T.: Ice nucleation properties of fine ash particles from the Eyjafjallajökull eruption in April 2010, Atmos. Chem. Phys., 11, 12945-12958, 
doi:10.5194/acp-11-12945-2011, 2011.

Wandinger, U.: Multiple-scattering influence on extinction- and backscatter-coefficient measurements with Raman and highspectral-resolution lidars, Appl. Optics, 37, 417-427, 1998.
Westbrook, C. D., Illingworth, A. J., O’Connor, E. J., and Hogan, R. J.: Doppler lidar measurements of oriented planar ice crystals falling from supercooled and glaciated layer clouds, Q. J. Roy. Meteorol. Soc., 136, 260-276, doi:10.1002/qj.528, 2010. 